\title{
Quality of Life Assessment in Older Adults with Dementia: A Systematic Review
}

\author{
Helen B. Burks ${ }^{a} \quad$ Jude K.A. des Bordes ${ }^{b}$ Riya Chadha ${ }^{a}$ Holly M. Holmes ${ }^{a}$ \\ Nahid J. Rianon ${ }^{a, b}$ \\ a Department of Internal Medicine, UTHealth McGovern Medical School, Houston, TX, USA; ${ }^{b}$ Department of Family \\ and Community Medicine, UTHealth McGovern Medical School, Houston, TX, USA
}

\section{Keywords}

Dementia · Older adults · Quality of life · Self-rating · Proxy rating

\begin{abstract}
Introduction: In the absence of a cure, dementia is often managed by minimizing risk factors contributing to quality of life (QOL). Attitudes to dementia in older adults may differ from those in relatively younger adults. The aim was to conduct a systematic review of the literature to determine how QOL was assessed in adults, 65 years and older with dementia, and identify factors that influence the reported scores. Methods: A systematic review of full-text articles addressing $\mathrm{QOL}$ in older adults with dementia, published in English from January 1995 to September 2020, was conducted using PubMed and PsycINFO. We included studies that assessed QOL and involved participants 65 years and older. Studies were evaluated for inclusion by 2 independent pairs of reviewers. We assessed the quality of the studies using the Joanna Briggs Institute's Critical Appraisal Checklist. Study characteristics and findings were summarized. Analysis was by narrative synthesis. We identified social and clinical factors influencing QOL scores. Results: Of the 1,010 articles
\end{abstract}

identified, 19 met the inclusion criteria. These 19 studies involved 6,279 persons with dementia, with sample sizes from 32 to 1,366 . Mean age of participants ranged from 77.1 to 86.6 years. Five measurement tools were identified; Quality of Life in Alzheimer Disease (QOL-AD), Alzheimer DiseaseRelated Quality of Life (ADRQL), Quality of Life in Late-Stage Dementia (QUALID), QUALIDEM (a dementia-specific QOL tool), and DEMQOL (health-related QOL for people with dementia). Self-ratings of QOL were higher than proxy ratings. Factors commonly influencing self-ratings of QOL included depression, functional impairment, and polypharmacy. Common factors that influenced proxy ratings included functional impairment, presence of neuropsychiatric symptoms, cognitive impairment, and caregiver burden. Conclusion: In evaluating QOL in dementia, self- and proxy reports may complement each other to ensure that all perspectives are addressed.

(c) 2021 S. Karger AG, Basel

Prior presentation: Part of the work was presented as abstracts at the following: 1. American Geriatric Society 2019 conference. 2. American Academy of Neurology 2020 conference.
Correspondence to:

Nahid J Rianon, nahid.j.rianon@uth.tmc.edu 


\section{Introduction}

Quality of life (QOL) has been previously defined as "individuals' perception of their position in life in the context of the culture and the value systems in which they live and in relation to their goals, expectations, standards, and concerns" $[1,2]$. There is inherent ambiguity in the definition for QOL due to the subjective nature of the measurement, and this ambiguity becomes especially problematic when QOL is used in the health-care setting as a metric for care [3]. QOL can be considered both subjectively related to a patient's experiences and personal values, as well as an objective measurement that can be altered to improve the lives of patients $[2,4,5]$. Though it is an extremely important metric for care, there is no gold standard to assess what QOL means for individuals nor is there a consensus over what factors most affect it $[6,7]$. One of the difficult aspects of assessing QOL is the subjective nature of the question itself, and this task becomes significantly more difficult when attempted in people with cognitive deficits such as in people with dementia.

Dementia is a group of different progressive diseases that currently has no cure. In diseases with limited disease modifying therapy, success of treatment is often measured by improving the QOL of the individual $[2,8]$. Dementia causes a decrease in cognitive function, so QOL has historically been reported by proxies such as family members or health-care providers [9]. While proxy-rated QOL (PRQOL) is common practice in many research settings, even individuals with moderate to severe dementia have the ability to rate their own QOL $[8,10]$. QOL in dementia could be used as an indicator of areas where health-care improvement is needed or as a rationale for further medical interventions [11]. However, several problems emerge when trying to use QOL as a health measure for people with dementia; QOL is currently not well defined for this population; there is no consensus on what factors most influence QOL and whether measurements of QOL by proxy accurately depict what QOL is for older people with dementia $[3,12]$.

While some studies have reviewed tools for assessing QOL in people with dementia as a whole, they were not restricted to older adults $[13,14]$. Considering the subjective nature of the QOL construct, it would be ideal if one could balance the importance of the items with the personal values of each individual [15]. The older adult may have unique issues. For example, dementia in the older adult may be associated with other competing risks of mortality. Thus attitudes to dementia in older adults may differ from those toward a younger population. There is the need therefore to look at QOL as it pertains to older adults with dementia. The aim of the study was to conduct a systematic review of the literature to determine how QOL was assessed in adults, 65 years and older with dementia, and identify factors that influence the reported scores.

\section{Methods}

The study was conducted in accordance with the PRISMA guidelines [16].

\section{Eligibility}

We included full-text papers written in English addressing QOL in older adults with dementia. Studies were included if participants were 65 years and older, had dementia, and the study's primary objective was the measurement of QOL. We only included articles if they had dementia-specific measures. Papers were excluded if they evaluated interventions, were psychometric studies of assessment tools, or if they included participants under 65 years. We also excluded review articles.

\section{Information Source and Search}

We conducted a systematic search in PubMed and PsycINFO using search terms "quality of life" and "dementia" for peer-reviewed articles published between January 1, 1995, and September 30,2020 . Search was restricted to "65 years and older". We used very broad search terms in order to capture all possible studies. We also searched references of the selected papers for additional studies.

\section{Study Selection}

Articles found in the original search were initially screened by 2 independent pairs of reviewers (H.B. and R.C.; J.D. and N.R.) for their relevance to the research question, using the titles and abstracts. Full texts of the selected articles were retrieved for further review and those that met the inclusion criteria were selected for analysis. Disagreements were resolved by consensus of at least 2 coauthors.

\section{Data Collection and Evaluation}

We extracted relevant information including the setting, number of participants, the use of Mini-Mental State Exam (MMSE) or equivalent measure of cognitive function in the subjects, average age of participants, instrument used for QOL measurement, and the main findings of the studies.

\section{Quality Appraisal}

All included studies were evaluated for quality using the Joanna Briggs Institute (JBI) critical appraisal tool for cross-sectional Studies [17]. The JBI appraisal checklist assesses quality based on 8 items. These included whether or not the criteria for inclusion was clearly defined, whether subjects and settings were described, whether the exposure was measured in a valid and reliable way and whether the condition was measured objectively. It also assesses whether confounding factors were identified, strategies defined for 
Fig. 1. Flowchart of study selection. QOL, quality of life.

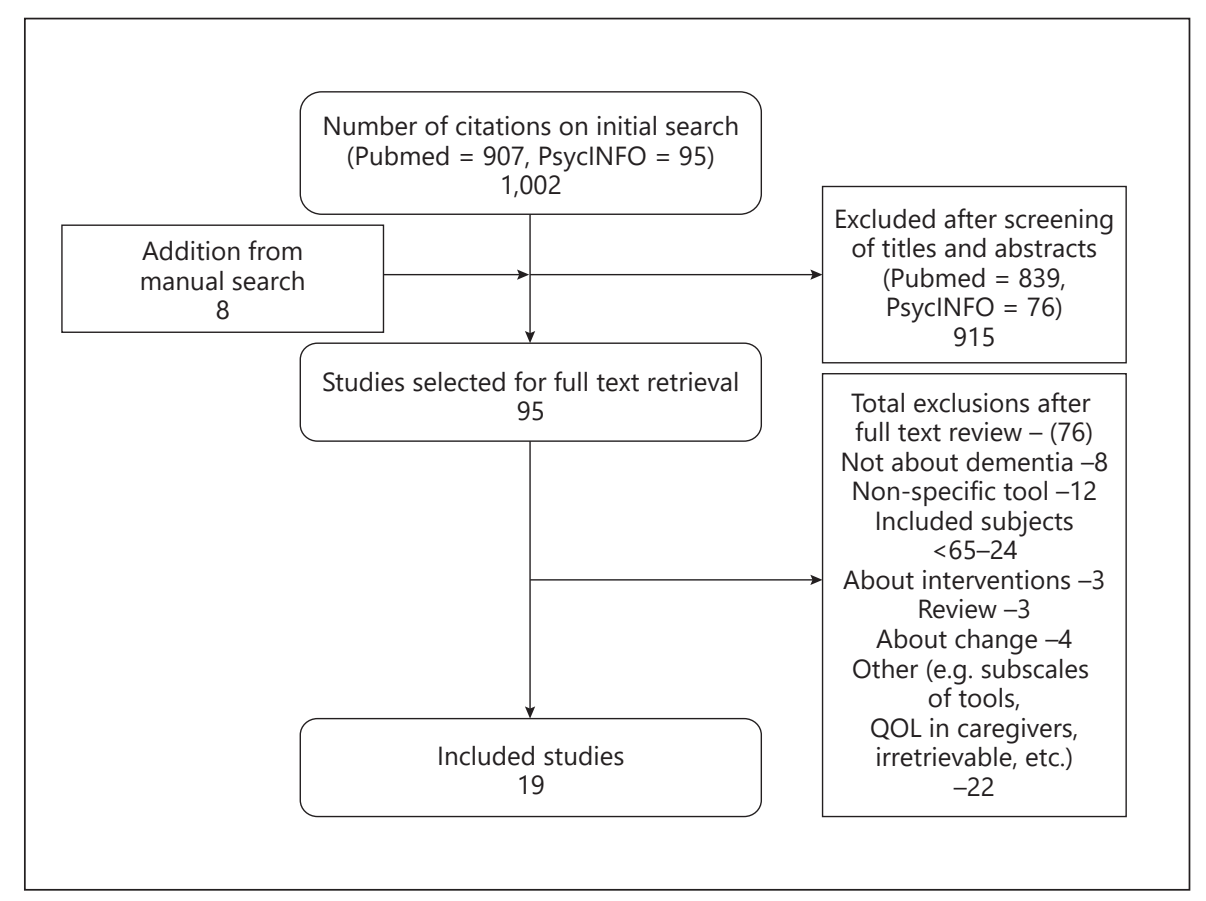

handling confounders, whether outcomes were measured in a valid and reliable manner and the appropriateness of the statistical analysis. Response options were "yes," "no," "unclear," and "not applicable" as appropriate. Percentage of studies meeting the various assessment criteria were calculated and summarized.

\section{Data Analysis}

Study characteristics and results were described and summarized using narrative synthesis. We described the selected studies by setting, including geographic location, type of participants, cognitive assessment tool, and main findings. The tools for assessment of QOL were also summarized.

\section{Results}

\section{Study Selection}

The initial search yielded 1,010 unique citations (PubMed, 907, PsycINFO, 95, and 8 from reference search). After initial review using the titles and abstracts, 915 papers were excluded. Ninety-five papers were selected for full-text retrieval and review. Seventy-six citations were further excluded for not meeting the inclusion criteria. Fig. 1 is a flow diagram of the study selection process.

\section{Study Characteristics}

Nineteen studies met the inclusion criteria $[1,10,18-$ 34]. Nine of the studies involved participants living in the community $[10,19,21,22,26-28,31,34]$, eight in longterm residential care facilities $[1,20,23-25,29,30,32]$, and two in both $[18,33]$. One of the studies was done in Australia [20], one in Brazil [10], 2 in Canada [27, 28], nine in continental Europe [1, 18, 19, 22, 24, 25, 32-34], 2 in Japan [29, 30], one in the United Kingdom [31], and three in the USA $[21,23,26]$. The studies involved a total of 6,279 persons with dementia, with sample sizes ranging from 32 to 1,366. Mean age of participants in the studies ranged from 77.1 to 86.6 years. Seven studies used both self-rated and proxy-rated measures [10, 18-22, 29], ten used proxy measures only [1, 23-26, 28, 32, 33], while 2 studies used self-rated measures [27,31]. MMSE was used in 14 studies to assess cognitive function [10, 18-22, 26$29,31-34]$. Seven articles compared self-reported QOL to proxy-reported QOL $[10,18-22,29]$. Table 1 is a summary of the selected studies and their characteristics (also see online suppl. Table 1; for all online suppl. material see www.karger.com/doi/10.1159/000515317).

\section{Quality Appraisal}

Six of the 8 quality criteria were met by all included studies. Sixteen out of the 19 selected studies (84.2\%) used objective and standard criteria for the measurement of dementia while 18 out of 19 studies (94.7\%) described study subjects and settings in detail (see online suppl. Fig. 1). 
Table 1. Summary of included studies

\begin{tabular}{|c|c|c|c|c|}
\hline Study & Setting/country & Participants, $n$ & Tools & Cognitive tool \\
\hline Barbe et al. [19] & Community, France, \& Switzerland & 123 & $\begin{array}{l}\text { QOL-AD (SR) } \\
\text { QOL-AD (PR) } \\
\text { QOL-AD (Total) }\end{array}$ & MMSE \\
\hline Beer et al. [20] & Residential care facility, Australia & 351 & $\begin{array}{l}\text { QOL-AD (SR) } \\
\text { QOL-AD (PR) } \\
\text { ADRQL (PR) }\end{array}$ & MMSE \\
\hline Bruvik et al. [22] & $\begin{array}{l}\text { Community } \\
\text { Norway }\end{array}$ & 231 & $\begin{array}{l}\text { QOL-AD (SR) } \\
\text { QOL-AD (PR) }\end{array}$ & MMSE \\
\hline Cordner et al. [23] & LTCF, USA & 119 & ADRQL (PR) & SIRS \\
\hline Graske et al. [25] & $\begin{array}{l}\text { LTCF } \\
\text { Germany }\end{array}$ & 133 & $\begin{array}{l}\text { ADRQL (PR) } \\
\text { QUALIDEM (PR) }\end{array}$ & $\begin{array}{l}\text { Medical diagnosis of } \\
\text { dementia }\end{array}$ \\
\hline Henskens et al. [32] & $\begin{array}{l}\text { LTCF } \\
\text { The Netherlands }\end{array}$ & 143 & QUALIDEM (PR) & MMSE \\
\hline Hodgson et al. [26] & Community, USA & 88 & DEMQOL-proxy & MMSE \\
\hline Klapwijk et al. [1] & $\begin{array}{l}\text { LTCF } \\
\text { The Netherlands }\end{array}$ & 288 & QUALIDEM (PR) & Reisberg GDS \\
\hline Missotten et al. [33] & $\begin{array}{l}\text { Community and LTCF } \\
\text { Belgium }\end{array}$ & 455 & ADRQL (PR) & MMSE \\
\hline Olsen et al. [34] & $\begin{array}{l}\text { Community } \\
\text { LTCF, Norway }\end{array}$ & 193 & QUALID (PR) & MMSE \\
\hline Romhild et al. [18] & $\begin{array}{l}\text { Community } \\
\text { LTCF, Europe }\end{array}$ & 1,330 & $\begin{array}{l}\text { QOL-AD (SR) } \\
\text { QOL-AD (PR) }\end{array}$ & MMSE \\
\hline Woods et al. [31] & Community, UK & 101 & QOL-AD (SR) & MMSE \\
\hline
\end{tabular}

LTCF, long-term care facility; MMSE, Mini-Mental State Examination; QOL-AD, Quality of Life in Alzheimer Disease; ADRQL, Alzheimer DiseaseRelated Quality of Life; QUALID, Quality of Life in Late-Stage Dementia; PR, proxy rated; SR, self-rated; SIRS, Severe Impairment Rating Scale; GDS, Global Deterioration Scale.

\section{Instruments Used}

Table 2 (see also online suppl. Table 2) is the list of tools identified in the studies that were used in assessing QOL and their characteristics. Five instruments were identified. Two of the tools were designed for both self- reporting by persons with dementia and proxy reporting by caregivers or health-care providers; these were Quality of Life in Alzheimer Disease (QOL-AD) and DEMQOL $[35,36]$. Among the tools designed for both self- and proxy report, the QOL-AD scale was used in 9 studies, 
Table 2. QOL instruments used and their characteristics

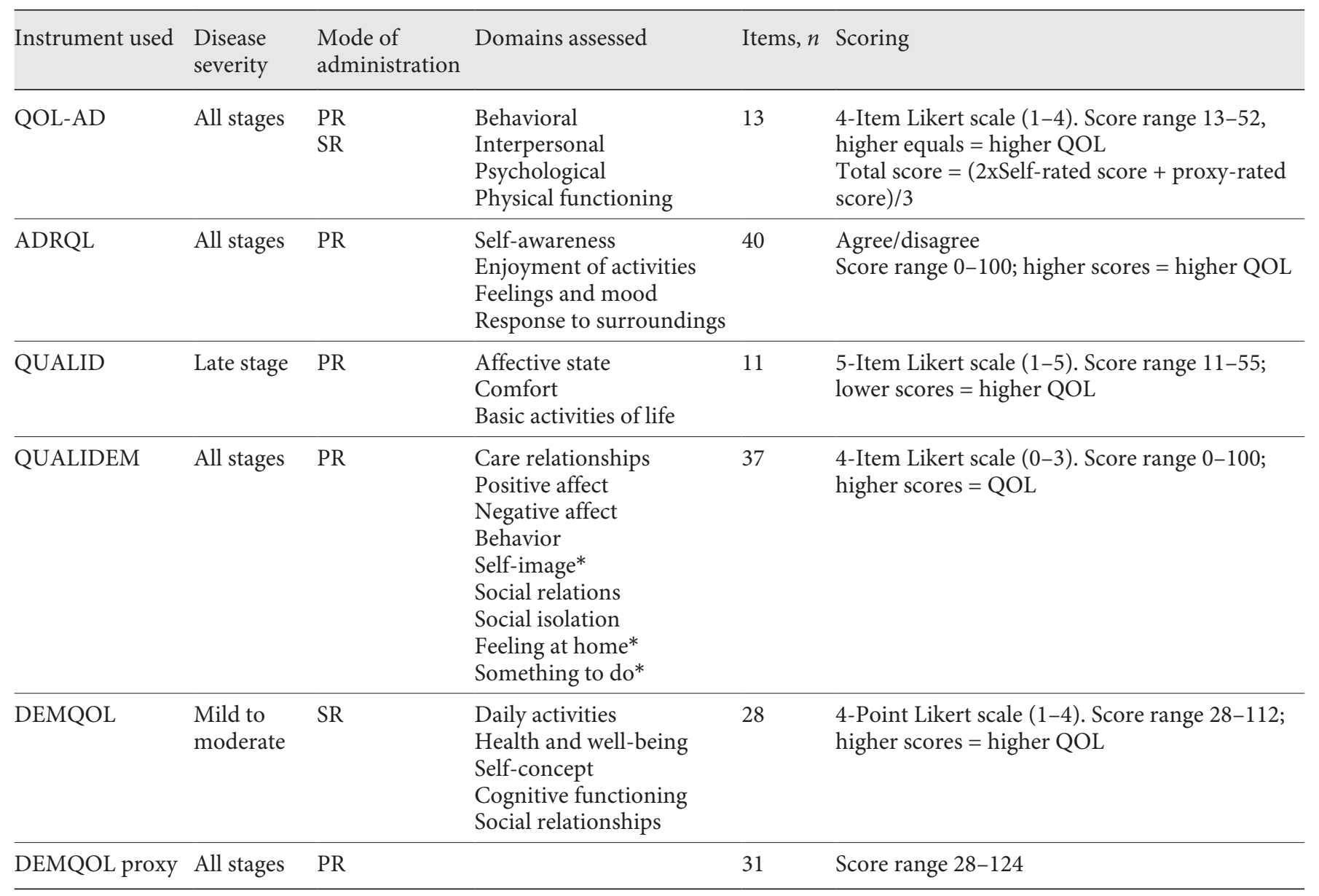

QOL, quality of life; QOL-AD, Quality of Life in Alzheimer Disease; ADRQL, Alzheimer Disease-Related Quality of Life; QUALID, Quality of Life in Late-Stage Dementia; PR, proxy rated; SR, self-rated. * Not included when used for severe disease.

seven of which used both the self-rated and proxy-rated tools. One study used only the self-rated QOL-AD [27], another study used only the proxy-rated QOL-AD [28], and one study [19] generated a total score by combining both the self-rated and proxy-rated scores. The Alzheimer Disease-Related Quality of Life (ADRQL) [37] scale, a proxy-rated instrument designed for use by trained interviewers in both community and residential settings, was used in 5 studies [21, 23, 25, 30, 33]. QUALIDEM [38], a dementia-specific QOL questionnaire rated by professionals was used in 3 studies [1, 25, 32]. QUALID [39], a proxy-rated QOL measure, was used in 2 studies [24, 34]. DEMQOL [36], a dementia-specific QOL evaluation tool designed for use by people with dementia or their proxies, was used in one study, as a proxy-rated measure [26].

A Review of Quality of Life Assessment in Dementia
Factors Influencing Self- and Proxy-Rating Scores

In studies that compared self-rated and proxy-rated scores, self-rated scores generally correlated with proxyrated scores. However, people with dementia tended to rate themselves higher than proxies [18-22, 29].

Most commonly reported factors that negatively influenced patient self-ratings of QOL included depression $[19,20,27,29,31]$, functional impairment $[22,29]$, and polypharmacy $[19,21]$. Other factors included number of unmet needs, presence of neuropsychiatric symptoms, pain, and use of physical restraints on them [20, 21, 27].

Commonly reported factors influencing proxy ratings of the QOL in dementia include functional impairment $[1,21,22,24,28-30]$, presence of neuropsychiatric symptoms $[1,20,21,23,25]$, and cognitive impairment $[1,20$, $21,23,26]$. Other factors include caregiver burden $[19,20$, 
$25]$, presence of comorbidities [1, 26], polypharmacy [19], pain [23, 26], sleep disruption [26], and hospitalizations [20]. One study reported no associations between self- or proxy-rated QOL and socioeconomic characteristics [10]. Proxy-rated QOL was higher in people with dementia living at home than those living in long-term care facilities [34]. People with dementia living in special group-living nursing homes were also rated higher in QOL than those living in traditional nursing homes when assessed by proxies [30].

\section{Discussion}

We did a systematic review of the literature to identify the various ways that QOL is assessed in the older population with dementia and to determine factors that influence how persons with dementia and their proxies perceive QOL in dementia. We identified 5 tools that had been used, and some factors that were associated with QOL scores.

The concept of QOL in dementia is an unsettled issue. This was reflected in the variations in the assessment tools in terms of data collection strategy (self-, proxy report or both), domains covered, settings (institutionalized or community living), and severity of dementia to be evaluated. In evaluating QOL in dementia, self- and proxy reports of QOL may complement each other to ensure that all perspectives are addressed.

Our results showed that the most commonly used tool was the QOL-AD. This corroborates findings of Bowling et al. [14] in their systematic review where QOL-AD was the most widely used tool. Results of studies that assessed both the proxy- and self-scores appeared to correlate. Patient-caregiver correlation of coefficient of 0.4 has been reported [40]. The QOL-AD has some advantages that probably made it the most used. It can be used for selfreport, proxy-reports or both. It is usable in both institutional and community settings and in all stages of dementia [15]. It assesses 4 domains with 13 items (Table 2; online suppl. Table 2) and takes less than $10 \mathrm{~min}$ to complete $[20,35]$. The self-report instrument is administered in an interview format whilst the proxy-report instrument is in a self-administered format. The ADRQL, can be used in all stages of dementia and is designed for proxy-reports. It is administered in an interview format by trained interviewers and has 40 items assessing 5 domains $[15,37]$. QUALID and QUALIDEM are proxy-rated tools suitable for institutional settings [38, 39]. QUALID is only for late-stage dementia, administered in a structured inter- view and has 11 items and evaluates 3 domains (Table 2) [39]. QUALIDEM has 37 items for the evaluation of 9 domains and is administered by trained interviewers [38]. DEMQOL and DEMQOL proxy can be used for selfreports and proxy-reports respectively and are suitable for mild to moderate (self) and all stages (proxy) of dementia in both community and institutional settings [36]. While the self-report tool has 28 items, the proxy-report instrument has 31 items (Table 2) [36]. DEMQOL is administered by interviews.

This search of the literature yielded several tools that could be used to determine QOL for older people with dementia, as well as factors that influenced QOL scores. Depression and functional impairment appear to be most common factors that negatively impact the QOL of the people with dementia. Functional impairment may be the most important factor affecting QOL of people with dementia [41]. Although depression may be independently associated with low QOL it could also be a proximate factor through which loss of function, unmet needs, disease burden, pain or physical restraints negatively impact QOL.

Proxy ratings were negatively impacted by functional impairment, presence of neuropsychiatric symptoms, cognitive impairment and depression in the participants. These may reflect the increased caregiver burden. Thus, caregiver burden may be a marker of other conditions that make the patient more dependent. Some studies have reported that QOL was positively associated with higher levels of cognitive function, though they found that subjects with less understanding of their disease, regardless of the level of cognitive impairment, had higher QOL [42]. Some factors that negatively correlated with QOL were the presence of pain and high disease burden. People with dementia who received adequate pain management were found to have higher QOL than those with untreated pain. While NPS contributed to lower QOL, the use of psychotropic medication was not shown to affect QOL. Some factors that negatively influenced QOL such as history of recent falls and frequent hospitalizations could be associated with physical impairment or disease burden.

While many studies rely on proxies as the sole reporter of QOL, this review indicated that using only PRQOL may not provide the complete picture of what makes up QOL. People with dementia can self-report their own QOL, even at higher levels of cognitive impairment [35]. Although proxy reports are still important to consider, it must be noted that there may be a bias toward reporting negative behaviors such as irritability and depression as playing a larger role in QOL than as perceived by people 
with dementia. Several of the proxy-rated studies also did not show as large a role for pain and comorbid conditions as it was indicated in self-reported questionnaires. This could lead to an under recognition and under treatment of pain or overprescribing psychiatric medications. One other large benefit to allowing more self-reporting for dementia is that PRQOL was consistently rated lower than SRQOL, which means that the persons with dementia feel that they have a higher QOL than what is in the majority of the literature, which could give relief to the families of dementia.

This review has some limitations. It includes studies from only 2 databases, PubMed and PsycINFO, and is published in English. Our review seemed to have reached saturation and a wider search might probably not have yielded much new information. We could not look at gender associations because not all the papers had the gender distribution of participants. We were also limited in distinguishing assessments by type of dementia, for example, Alzheimer's dementia and vascular dementia. Some earlier reviews identified more dementia-specific QOL instruments than those reported in our study, but those studies were not limited to patients over 65 years $[14,42,43]$. This review looked for measures that have been used in older persons with dementia, specifically those 65 years and older, and therefore was limited in scope to report those tools. However, most of our included studies being higher quality according to the JBI appraisal tool (online suppl. Fig. 1) makes this review a strong source of evidence about current literature on how QOL is measured in older adults with dementia.

Our review indicates it might be better to use reports from both self- and proxy-rated QOL to assess QOL in dementia where possible. Studies show that individuals with dementia are able to self-report their own QOL even with a high level of cognitive impairment [35]. Although many studies consider MMSE score of 10 as cutoff for using a self-rating scale, participants with MMSE score of as low as 4 had been able to complete a self-rating assessment [35].Therefore, when appropriate, we recommend both self- and proxy-reports when assessing QOL in persons with dementia. Self-report measures are the preferred methods when feasible but must be complemented by proxy reports where applicable. An input from the clinician, for example, geriatrician, may help identify applicable cases. One tool, QOL-AD, offers a composite or combined score by assigning a weight of 2 to self-reports and one to proxy. It is difficult to ascertain how to assign weights. It may be useful to also consider measures of caregiver well-being (such as caregiver burden and/or de- pression) when only proxy scores are used since the proxy scores may reflect the state of the caregiver as well. The use of different instruments measuring different domains shows the complexity in defining what constitutes QOL in this population. Various settings of research may mean various levels of functional and cognitive abilities in people with dementia.

\section{Statement of Ethics}

This study does not involve human subjects and does not require ethical approval by Committee for the Protection of Human Subjects of the University of Texas Health Science Center, Houston.

\section{Conflict of Interest Statement}

The authors declare no conflicts of interest.

\section{Funding Sources}

Not applicable.

\section{Author Contributions}

Conception and design of study: Helen Burks and Nahid Rianon. Data acquisition, analysis, and interpretation: Jude des Bordes, Helen Burks, Riya Chadha, Helen Burks, and Holly Holmes. Drafting and revising for critical intellectual content: Helen Burks, Jude des Bordes, Riya Chadha, Nahid Rianon, and Holly Holmes. Final approval of manuscript: Helen Burks, Jude des Bordes, Riya Chadha, Nahid Rianon, and Holly Holmes. Accountability for accuracy or integrity of the work: Helen Burks, Jude des Bordes, Riya Chadha, Nahid Rianon, and Holly Holmes.

\section{References}

1 Klapwijk MS, Caljouw MA, Pieper MJ, van der Steen JT, Achterberg WP. Characteristics associated with quality of life in long-term care residents with dementia: a cross-sectional study. Dement Geriatr Cogn Disord. 2016;42(3-4):18697.

2 Telenius EW, Engedal K, Bergland A. Physical performance and quality of life of nursing-home residents with mild and moderate dementia. Int J Environ Res Public Health. 2013;10(12):667286.

3 Arons AM, Krabbe PF, Schölzel-Dorenbos CJ, van der Wilt GJ, Rikkert MG. Quality of life in dementia: a study on proxy bias. BMC Med Res Methodol. 2013;13:110. 
4 Bramston P, Tomasevic V. Health locus of control, depression and quality of life in people who are elderly. Australas J Ageing. 2001;20(4):1925.

5 Covinsky KE, Wu AW, Landefeld CS, Connors AF Jr, Phillips RS, Tsevat J, et al. Health status versus quality of life in older patients: does the distinction matter?. Am J Med. 1999;106(4): $435-40$.

6 Moriarty J, Butt J. Inequalities in quality of life among older people from different ethnic groups. Ageing Soc. 2004;24(5):729-53.

7 Torisson G, Stavenow L, Minthon L, Londos E. Reliability, validity and clinical correlates of the Quality of Life in Alzheimer's disease (QoL-AD) scale in medical inpatients. Health Qual Life Outcomes. 2016;14:90.

8 Moyle W, Fetherstonhaugh D, Greben M, Beattie E. Influencers on quality of life as reported by people living with dementia in long-term care: a descriptive exploratory approach. BMC Geriatr. 2015;15:50.

9 Hurt C, Bhattacharyya S, Burns A, Camus V, Liperoti R, Marriott A, et al. Patient and caregiver perspectives of quality of life in dementia. An investigation of the relationship to behavioural and psychological symptoms in dementia. Dement Geriatr Cogn Disord. 2008;26(2):138-46.

10 Dourado MC, Sousa MF, Santos RL, Simões JP, Nogueira ML, Belfort TT, et al. Quality of life in mild dementia: patterns of change in self and caregiver ratings over time. Rev Bras Psiquiatr. 2016;38(4):294-300.

11 Heyland DK, Dodek P, You JJ, Sinuff T, Hiebert $\mathrm{T}$, Tayler $\mathrm{C}$, et al. Validation of quality indicators for end-of-life communication: results of a multicentre survey. Cmaj. 2017;189(30):E980-989.

12 Dementia from the inside: how people with early-stage dementia evaluate their quality of life. Nurs Old People. 2006;17 (10):33.

13 Ready RE, Ott BR. Quality of Life measures for dementia. Health Qual Life Outcomes. 2003;1: 11.

14 Bowling A, Rowe G, Adams S, Sands P, Samsi K, Crane M, et al. Quality of life in dementia: a systematically conducted narrative review of dementia-specific measurement scales. Aging Ment Health. 2015;19(1):13-31

15 Missotten P, Dupuis G, Adam S. Dementia-specific quality of life instruments: a conceptual analysis. Int Psychogeriatr. 2016;28(8):1245-62.

16 Moher D, Liberati A, Tetzlaff J, Altman DG. Preferred reporting items for systematic reviews and meta-analyses: the PRISMA statement. J Clin Epidemiol. 2009;62(10):1006-12.

17 Moola S, Munn Z, Tufanaru C, Aromataris E, Sears K, Sfetcu R, et al. Chapter 7: systematic reviews of etiology and risk. Joanna Briggs Institute Reviewer's Manual. The Joanna Briggs Institute; 2017.

18 Romhild J, Fleischer S, Meyer G, Stephan A, Zwakhalen S, Leino-Kilpi $\mathrm{H}$, et al. Inter-rater agreement of the Quality of Life-Alzheimer's Disease (QoL-AD) self-rating and proxy rating scale: secondary analysis of RightTimePlaceCare data. Health Qual Life Outcomes. 2018;16(1): 131.

19 Barbe C, Jolly D, Morrone I, Wolak-Thierry A, Dramé M, Novella JL, et al. Factors associated with quality of life in patients with Alzheimer's disease. BMC Geriatr. 2018;18(1):159.

20 Beer C, Flicker L, Horner B, Bretland N, Scherer $\mathrm{S}$, Lautenschlager NT, et al. Factors associated with self and informant ratings of the quality of life of people with dementia living in care facilities: a cross sectional study. PLoS One. 2010; 5(12):e15621.

21 Black BS, Johnston D, Morrison A, Rabins PV, Lyketsos CG, Samus QM. Quality of life of community-residing persons with dementia based on self-rated and caregiver-rated measures. Qual Life Res. 2012;21(8):1379-89.

22 Bruvik FK, Ulstein ID, Ranhoff AH, Engedal K. The quality of life of people with dementia and their family carers. Dement Geriatr Cogn Disord. 2012;34(1):7-14.

23 Cordner Z, Blass DM, Rabins PV, Black BS. Quality of life in nursing home residents with advanced dementia. J Am Geriatr Soc. 2010; 58(12):2394-400.

24 Goyal AR, Bergh S, Engedal K, Kirkevold M, Kirkevold $\varnothing$. Trajectories of quality of life and their association with anxiety in people with dementia in nursing homes: a 12-month follow-up study. PLoS One. 2018;13(9):e0203773.

25 Graske J, Meyer S, Wolf-Ostermann K. Quality of life ratings in dementia care-a cross-sectional study to identify factors associated with proxyratings. Health Qual Life Outcomes. 2014;12: 177.

26 Hodgson N, Gitlin LN, Huang J. The influence of sleep disruption and pain perception on indicators of quality of life in individuals living with dementia at home. Geriatr Nurs. 2014;35(5): 394-8.

27 Naglie G, Hogan DB, Krahn M, Beattie BL, Black SE, Macknight C, et al. Predictors of patient selfratings of quality of life in Alzheimer disease: cross-sectional results from the Canadian $\mathrm{Al}$ zheimer's Disease Quality of Life Study. Am J Geriatr Psychiatry. 2011;19(10):881-90.

28 Naglie G, Hogan DB, Krahn M, Black SE, Beattie BL, Patterson C, et al. Predictors of family caregiver ratings of patient quality of life in Alzheimer disease: cross-sectional results from the Canadian Alzheimer's Disease Quality of Life Study. Am J Geriatr Psychiatry. 2011;19(10):891-901.

29 Nakanishi K, Hanihara T, Mutai H, Nakaaki S. Evaluating the quality of life of people with dementia in residential care facilities. Dement Geriatr Cogn Disord. 2011;32(1):39-44.

30 Nakanishi M, Nakashima T, Sawamura K. Quality of life of residents with dementia in a groupliving situation: an approach to creating small, homelike environments in traditional nursing homes in Japan. Nihon Koshu Eisei Zasshi. 2012; 59(1):3-10.

31 Woods RT, Nelis SM, Martyr A, Roberts J, Whitaker CJ, Markova I, et al. What contributes to a good quality of life in early dementia?
Awareness and the QoL-AD: a cross-sectional study. Health Qual Life Outcomes. 2014;12:94.

32 Henskens M, Nauta IM, Vrijkotte S, Drost KT, Milders MV, Scherder EJA. Mood and behavioral problems are important predictors of quality of life of nursing home residents with moderate to severe dementia: a cross-sectional study. PLoS One. 2019;14(12):e0223704.

33 Missotten P, Thomas P, Squelard G, Di Notte D, Fontaine O, Paquay L, et al. Impact of place of residence on relationship between quality of life and cognitive decline in dementia. Alzheimer Dis Assoc Disord. 2009;23(4):395-400.

34 Olsen C, Pedersen I, Bergland A, Enders-Slegers MJ, Jøranson N, Calogiuri G, et al. Differences in quality of life in home-dwelling persons and nursing home residents with dementia - a crosssectional study. BMC Geriatr. 2016;16:137.

35 Logsdon RG, Gibbons LE, McCurry SM, Teri L. Assessing quality of life in older adults with cognitive impairment. Psychosom Med. 2002;64(3): 510-9.

36 Smith SC, Lamping DL, Banerjee S, Harwood R, Foley B, Smith P, et al. Measurement of healthrelated quality of life for people with dementia: development of a new instrument (DEMQOL) and an evaluation of current methodology. Health Technol Assess. 2005;9(10):1-93.

37 Rabins PV, Kasper JD, Kleinman L, Black BS, Patrick DL. Concepts and methods in the development of the ADRQL: an instrument for assessing health-related quality of life in persons with Alzheimer's disease. J Mental Health Aging. 1999;5(1):33-48.

38 Ettema TP, Dröes RM, de Lange J, Mellenbergh GJ, Ribbe MW. QUALIDEM: development and evaluation of a dementia specific quality of life instrument. Scalability, reliability and internal structure. Int J Geriatr Psychiatry. 2007;22(6): 549-56.

39 Weiner MF, Martin-Cook K, Svetlik DA, Saine $\mathrm{K}$, Foster B, Fontaine CS. The quality of life in late-stage dementia (QUALID) scale. J Am Med Dir Assoc. 2000;1(3):114-6.

40 Logsdon RG, Gibbons LE, McCurdy SA, Teri L. Quality of life in Alzheimers disease: patient and caregiver reports. J Ment Health Aging. 1999; 5(1):21-32.

41 Andersen CK, Wittrup-Jensen KU, Lolk A, Andersen K, Kragh-Sørensen P. Ability to perform activities of daily living is the main factor affecting quality of life in patients with dementia. Health Qual Life Outcomes. 2004;2:52.

42 Stites SD, Karlawish J, Harkins K, Rubright JD, Wolk D. Awareness of mild cognitive impairment and mild Alzheimer's disease dementia diagnoses associated with lower self-ratings of quality of life in older adults. J Gerontol B Psychol Sci Soc Sci. 2017;72(6):974-85.

43 Scholzel-Dorenbos CJ, Ettema TP, Bos J, Boelens-van der Knoop E, Gerritsen DL, Hoogeveen F, et al. Evaluating the outcome of interventions on quality of life in dementia: selection of the appropriate scale. Int J Geriatr Psychiatry. 2007; 22(6):511-9. 